\title{
Negative GBS Risk Status
}

National Cancer Institute

\section{Source}

National Cancer Institute. Negative GBS Risk Status. NCI Thesaurus. Code C111948.

Rectal/vaginal culture negative for group B Streptococcus (GBS) within 5 weeks. 